\title{
Complex Genetic Alterations in Gastrointestinal Stromal Tumors with Autonomic Nerve Differentiation
}

\author{
Maria Debiec-Rychter, M.D., Ph.D., Patrick Pauwels, M.D., Jerzy Lasota, M.D., Ph.D., \\ Sabine Franke, Ph.D., Rita De Vos, M.D., Ph.D., Ivo de Wever, M.D., Ph.D., \\ Anne Hagemeijer, M.D., Ph.D., Raf Sciot, M.D., Ph.D. \\ Center for Human Genetics (MD-R, AH, SF), Laboratory for Morphology and Molecular Pathology (RDV, \\ $R S)$, and Department of Surgery (IdW), Katholieke Universiteit Leuven, Belgium; Stichting PAMM (PP), \\ Catharinaziekenhuis, Eindhoven, the Netherlands; Department of Soft Tissue Pathology, Armed Forces \\ Institute of Pathology (JL), Washington, DC
}

Gastrointestinal stromal tumors (GISTs) with neurogenic differentiation, also referred to as "gastrointestinal autonomic nerve tumors (GANTs)," form an ultrastructurally distinctive subgroup of mesenchymal neoplasms of gastrointestinal tract. Cytogenetic and molecular data of these tumors are limited. In the current study, c-KIT gene sequencing analysis, comparative genomic hybridization (CGH), and interphase fluorescence in situ hybridization (FISH) analysis, utilizing chromosome 14and 22-specific probes, were performed on five primary ultrastructurally confirmed GANTs. FISH and CGH analysis revealed loss of a whole or part of chromosome $14 \mathrm{q}$ in two tumors and of chromosome 22q, with the common overlapping area of loss at q13, in all five tumors evaluated. c-KIT mutations were found in all cases; three tumors carried point mutation and/or deletions of exon 11, and in two tumors, insertion in exon 9 was found. These findings suggest that accumulated genetic changes contribute to the pathogenesis of GANTs and that 22q13 loss may be a characteristic feature of these tumors.

KEY WORDS: Chromosome 14, Chromosome 22, c-KIT mutation, GANT, GIST.

Mod Pathol 2002;15(7):692-698

Copyright () 2002 by The United States and Canadian Academy of Pathology, Inc.

VOL. 15, NO. 7, P. 692, 2002 Printed in the U.S.A.

Date of acceptance: March 22, 2002.

This article presents research results of the Belgian program on Interuniversity Poles of Attraction initiated by the Belgian State, Prime Minister's Office, Science Policy Programming. The authors assume scientific responsibility.

Address reprint requests to: Maria Debiec-Rychter, Center for Human Genetics, Katholieke Universiteit Leuven, O \& N Gasthuisberg, Herestraat 49, 3000 Leuven, Belgium; e-mail: maria.debiec-rychter@med.kuleuven. ac.be; fax: 32-16-346063.

DOI: 10.1097/01.MP.0000017564.15834.1F
Gastrointestinal stromal tumors (GISTs) represent the distinct mesenchymal tumors of the gastrointestinal tract with a wide morphological spectrum and various degrees of differentiation toward interstitial cells of the Cajal phenotype (1). Perhaps the most specific and relevant diagnostic criterion for GISTs is the immunohistochemically determined C-KIT proto-oncogene expression $(2,3)$; the latter encodes for a transmembrane tyrosine-kinase receptor (CD117) and has the stem cell factor as its ligand.

The identification of gastrointestinal autonomic nerve tumors (GANTs), originally described under the name plexosarcomas, was based on ultrastructural similarities with the myenteric plexus of the gastrointestinal tract $(4-7)$. Recent evidence indicates considerable morphologic, immunophenotypic, and molecular overlap between GANTs and GISTs, most significantly the common CD117 immunopositivity and the presence of c-KIT mutations (8); most likely tumors previously described as GANTs represent an ultrastructural subset of GISTs with peculiar neuroaxonal characteristics.

Although the data on the pathogenesis of GISTs rapidly have been growing over the last few years, the genetic changes leading to the initiation and progression of GISTs are still only partially known. Gain of function c-KIT mutations were found in extracellular, juxtamembrane, and kinase domains of the majority of GISTs, presumably contributing to the molecular initiation of these neoplasms (912). Additionally, the karyotypic and fluorescence in situ hybridization (FISH) analysis, and the studies of DNA copy number changes by comparative genomic hybridization (CGH) and loss of heterozygosity, demonstrated losses in chromosome 14q, detected in $\leq 85 \%$ (13-15), and in $22 \mathrm{q}$, detected in $\leq 77 \%$ of benign and malignant GISTs $(13,16,17)$. The recurrent losses of chromosomal material strongly suggest other alterations, in addition to the 
c-KIT mutations, to be involved in tumorigenesis and/or in the progression of GISTs. These alterations may contribute to heterogeneous differentiation patterns and clinical behavior of GISTs. In contrast to conventional GISTs, however, the cytogenetic and molecular data on GANTs are limited $(8,15)$. The purpose of this study was to analyze the presence of c-KIT mutations and the pattern of deletions in chromosome 14 and 22 in cases of well-delineated GANTs to clarify to what extent they contribute to their pathogenesis.

\section{MATERIALS AND METHODS}

Five primary intra-abdominal neoplasms diagnosed as GANT were included in the study. Patient 1, a 25-year-old woman, presented with a duodenal tumor mass that measured $2 \mathrm{~cm}$ in diameter and showed low mitotic activity (1 mitosis/10 high-power fields [HPF]) (18). The tumor was diagnosed as "probably benign." However, 8 years later, multiple peritoneal and liver metastases developed, and the patient died 10 years after the primary diagnosis. The clinical and histopathological data on the four other patients have been described elsewhere (15). They are summarized in Table 1.

\section{Histopathology}

Histopathologic examination and immunohistochemical analyses were performed on tissue fixed in $10 \%$ buffered formalin and embedded in paraffin. Immunohistochemical/studies were performed using polyclonal antibodies against CD117 (dilution 1/50; DAKO, Denmark) and S100 protein (dilution 1/300, DAKO) and monoclonal antibodies against CD34 (dilution 1/50, DAKO), $\alpha$-smooth muscle actin (dilution 1/400, Sigma, Israel), and desmin (dilution 1/20, ICN-Cappel, Belgium) and subsequently detected with avidin-biotin peroxidase complex system and diaminobenzidine as the chromogen. Ultrastructural analysis was performed on $2.5 \%$ glutaraldehyde-fixed tumor fragments.

\section{FISH Analysis}

Dual-color FISH was performed on slides prepared from available cell suspension containing single cells obtained after overnight collagenase treatment of tumor specimens. The slides were fixed in a 3:1 mixture of methanol and acetic acid and stored at $-20^{\circ} \mathrm{C}$ until they were analyzed. In the case of primary tumor from Patient 1 , FISH was performed on nuclei extracted from paraffinembedded tissue. Nuclei extraction was done as described elsewhere (19).

For the assessment of chromosome 14 loss, the yeast artificial chromosome (YAC) clones, isolated from the Center d'Etude du Polymorphisme Humain (CEPH, Paris, France) human genomic YAC libraries and corresponding to $14 \mathrm{q} 12-\mathrm{q} 32$, were used, as described elsewhere (15). Applied DNA probes were labeled with biotin-16-dUTP or digoxigenin-11-dUTP and used in pairs.

For the analysis of chromosome 22 loss, the following sets of probes were used: SpectrumGreenand SpectrumOrange-labeled LSI 22q11.2/22q13.3 (DGCR/ARSA loci, Vysis Inc., Downers Grove, IL), SpectrumGreen-labeled LSI 22q11.2 (BCR locus, Vysis Inc.) together with digoxigenin-labeled cosmid G9 (corresponding to 22q12, proximal to EWSR1 region) or digoxigenin-labeled 96C10 (NF2/ 22q12 locus; kindly provided by Dr E. Zwarthoff, Rotterdam). Hybridization and detection were performed as previously described (20). Hybridization signals were analyzed by using an Axioplan 2 fluorescence/microscope equipped with a cooled CCD camera and run by Cytogen system for capture and analysis (Imstar S.A., Paris, France). The number of hybridization signals for each specimen was assessed in 100 interphase nuclei. A specimen was interpreted as monosomic if only one signal for each respective probe was detected in $>25 \%$ of the cells evaluated (more than three standard deviations above the average false-positive rate observed in control experiments on nuclei extracted from paraffin-embedded tissue).

\section{TABLE 1. Clinical and Histological Features of GANTs from Five Patients and Outcome of the Disease}

\begin{tabular}{|c|c|c|c|c|}
\hline Case Number/Patient ID & Sex/Age & Tumor Site/Size in $\mathrm{cm} /$ Mitoses & $\begin{array}{l}\text { Clinical Status at } \\
\text { Presentation }\end{array}$ & Outcome of the Disease \\
\hline 1. $152227^{a}$ & $\mathrm{~F} / 25$ & Duodenum $/ 2 \times 2 \times 2 / 1 / 10 \mathrm{HPF}$ & Primary & $\begin{array}{l}\text { Peritoneal seeding } 8 \text { years from } \\
\text { the first presentation, DOD } \\
10 \text { years }\end{array}$ \\
\hline 2. $153420^{b}$ & $\mathrm{M} / 78$ & Colon $/ 4 \times 3 \times 1 / 6 / 10 \mathrm{HPF}$ & $\begin{array}{l}\text { Primary, omental } \\
\text { seeding }\end{array}$ & DOD 38 months \\
\hline 3. $177678^{b}$ & $\mathrm{M} / 31$ & Sm.I./10×22×12/6/10 HPF & Liver metastases & DOD 36 months \\
\hline 4. $221544^{b}$ & $\mathrm{M} / 38$ & Omentum/10×9 $\times 7 / 5 / 10 \mathrm{HPF}$ & Primary & AWD 18 month \\
\hline 5. $225368^{b}$ & $\mathrm{M} / 41$ & I.A. $/ 10 \times 10 /<1 / 10 \mathrm{HPF}$ & $\begin{array}{l}\text { Primary, omental } \\
\text { metastasis }\end{array}$ & AWD 16 month \\
\hline
\end{tabular}

${ }^{a}$ Previously published (18); ${ }^{b}$ Previously published (15).

Sm.I., small intestine; I.A., intra-abdominal; DOD, died of the disease; AWD, alive with the disease, currently under STI-571 treatment. 


\section{CGH Analysis}

Comparative genomic hybridization (CGH) was performed using DNA extracted from frozen tissue (all but one tumor) or from paraffin-embedded tissue (primary tumor from Patient 1), according to the method described by Kallioniemi and coworkers (21), with minor modification (22). The image analysis was performed using an epifluorescence microscope (Leica DMRB, Wetzlar, Germany) and image analysis software (QUIPS, Vysis, IL). The ratio of FITC/Lissamine fluorescence intensities obtained from 10 metaphase spreads per case were averaged, and the resulting profile was blotted next to the ideogram. Ratios above 1.2 and below 0.8 were considered to represent chromosomal gains and losses, respectively.

\section{Molecular Studies}

DNA for PCR amplification was obtained from fresh tissue or from paraffin-embedded material by standard methods. Exons 9, 11, 13 and 17 of the c-KIT gene was evaluated for the mutations by polymerase chain reaction amplification and direct sequencing of the amplification products, as described elsewhere $(12,23,24)$.

\section{RESULTS}

Histological and Ultrastructural Appearance

Histologically, all tumors showed a spindle cell pattern (Fig. 1). All were strongly and diffusely immunoreactive with CD117 antibody, and all were negative for desmin and S100 protein. Three tumors were stained with CD34 antibody (from Patients 2,3 , and 5), revealing multifocal immunopositivity. In two tumors, focal $\alpha$-smooth muscle actin expression was seen.

Ultrastructurally, the tumors consisted of nests and bundles of spindle-shaped cells, exhibiting elongated nuclei with peripheral and dispersed small clumps of heterochromatin. Some of these cells revealed long interdigitating cytoplasmic processes with short intermediate junctions. The presence of variable numbers of bulbous axonlike processes, containing many small empty vesicles and dense core granules of various diameters, was frequently observed. The intercellular spaces contained aberrant skeinoid fibers (extracellular collagen globules; Figs. 2 and 3).

\section{FISH and CGH Analysis}

A summary of the cytogenetic, FISH, and CGH findings is provided in Table 2. By interphase FISH

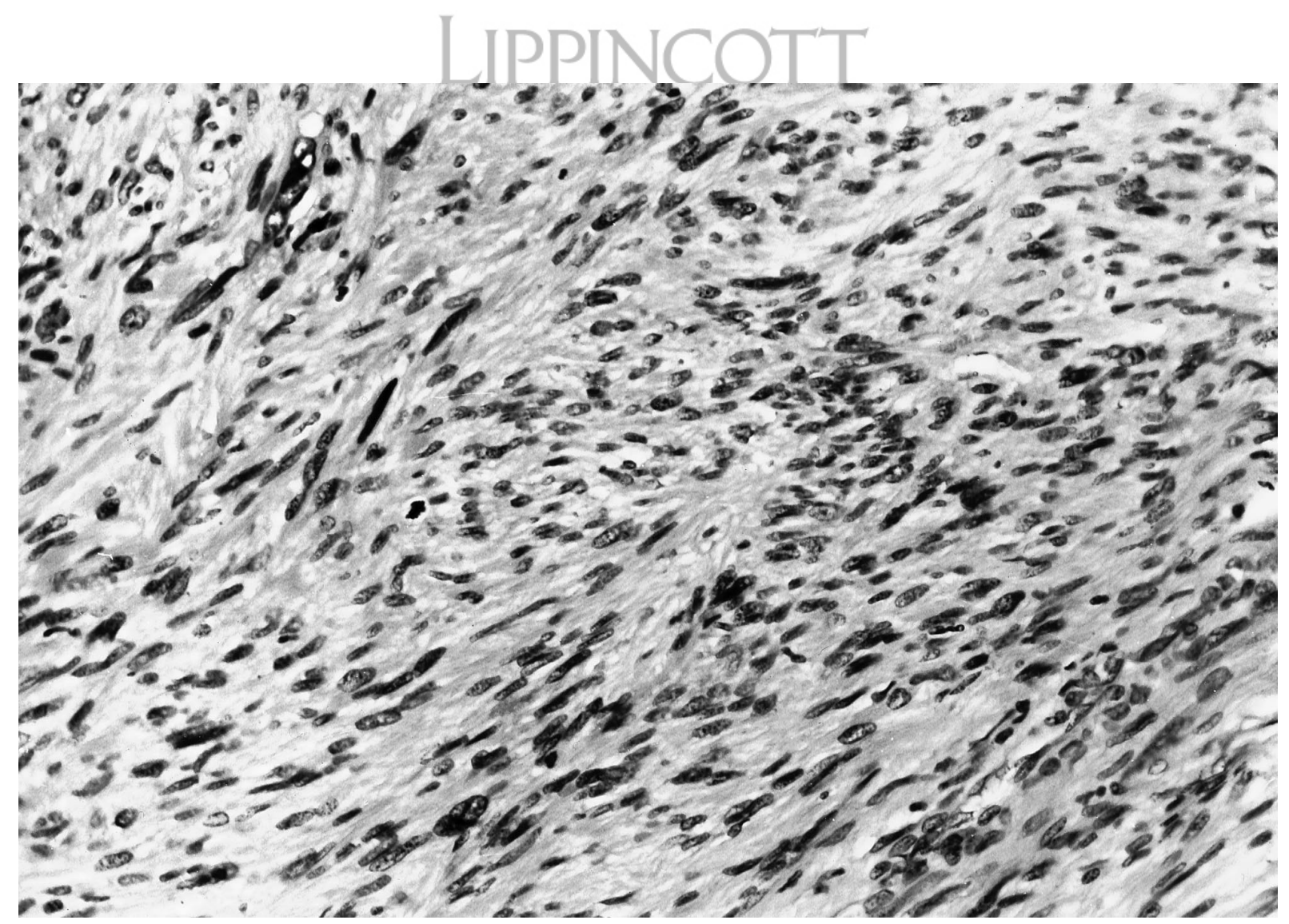

FIGURE 1. Spindle cell pattern of colon GANT from Patient 2, which is virtually indistinguishable from classical GIST. Hematoxylin and eosin staining. 


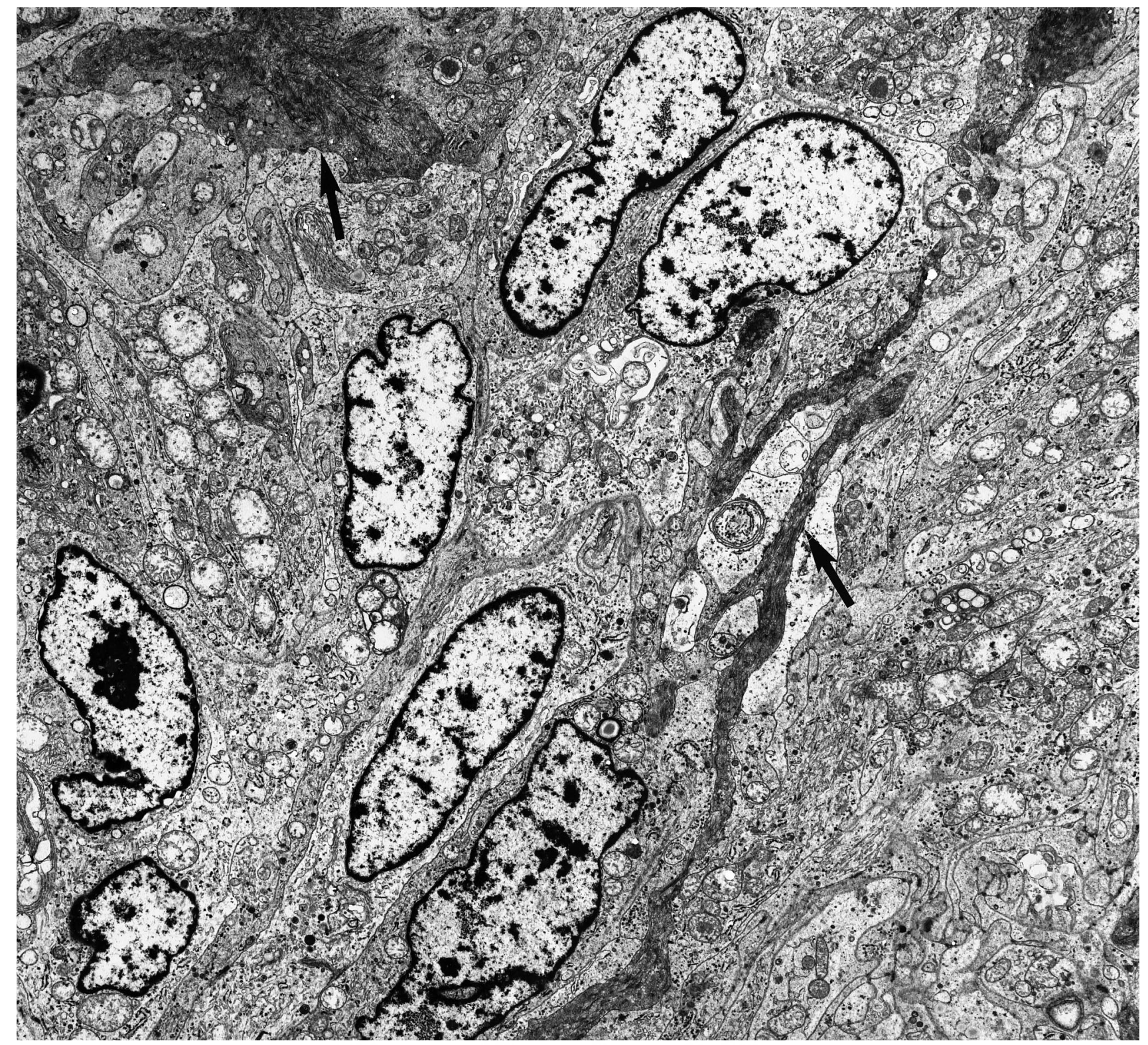

FIGURE 2. Electron micrograph of a group of spindle-shaped tumor cells with cellular processes. Note skeinoid fibers (arrow). Magnification, $4,600 \times$

using chromosome 14-specific probes, the primary tumor of Patient 1 revealed normal, biallelic chromosome 14 complement in $91 \%$ of cells. However, in the recurrent specimen from this patient, the entire 14q11-q32 region was lost in $38 \%$ of nuclei. In this case, the loss of chromosome 14 in a subpopulation of recurrent malignant cells proves the secondary character of this genetic change, occurring most likely because of tumor progression. The results of cytogenetic analysis and dual-color FISH evaluation of 14q11-q32 losses in Cases 2-5 had been published before (15). As is summarized in Table 2, specimens from Patients 2 and 3 did not reveal chromosome 14 losses, whereas tumors from Patients 4 and 5 revealed deletions of 14q23-q24 and 14q11-q32 regions, in 55 and $93 \%$ of cells, respectively.
Dual-color FISH with the $22 \mathrm{q}$ region-specific probes revealed partial chromosome 22 losses in all five specimens. In Patient 1, 76 and $87 \%$ of nuclei showed 22q12-13 loss in the primary and recurrent tumor specimens, respectively, whereas the entire chromosome 22 loss was seen in $40 \%$ of cells in the recurrent sample. Again, the terminal partial 22q12-13 loss could be the primary genetic event, whereas the loss of the entire chromosome 22 sequences could be the progression-type genetic event in this tumor.

Tumor from Patient 5 showed total chromosome 22 loss, as the specimens from Patients 2 and 4 revealed partial 22q12-qter, and those from Patient 3 , only 22 q13.3 deletions. In particular, the probe specific for NF2/22q12 loci (cosmid 96C10) showed normal biallelic presence in the latter. 


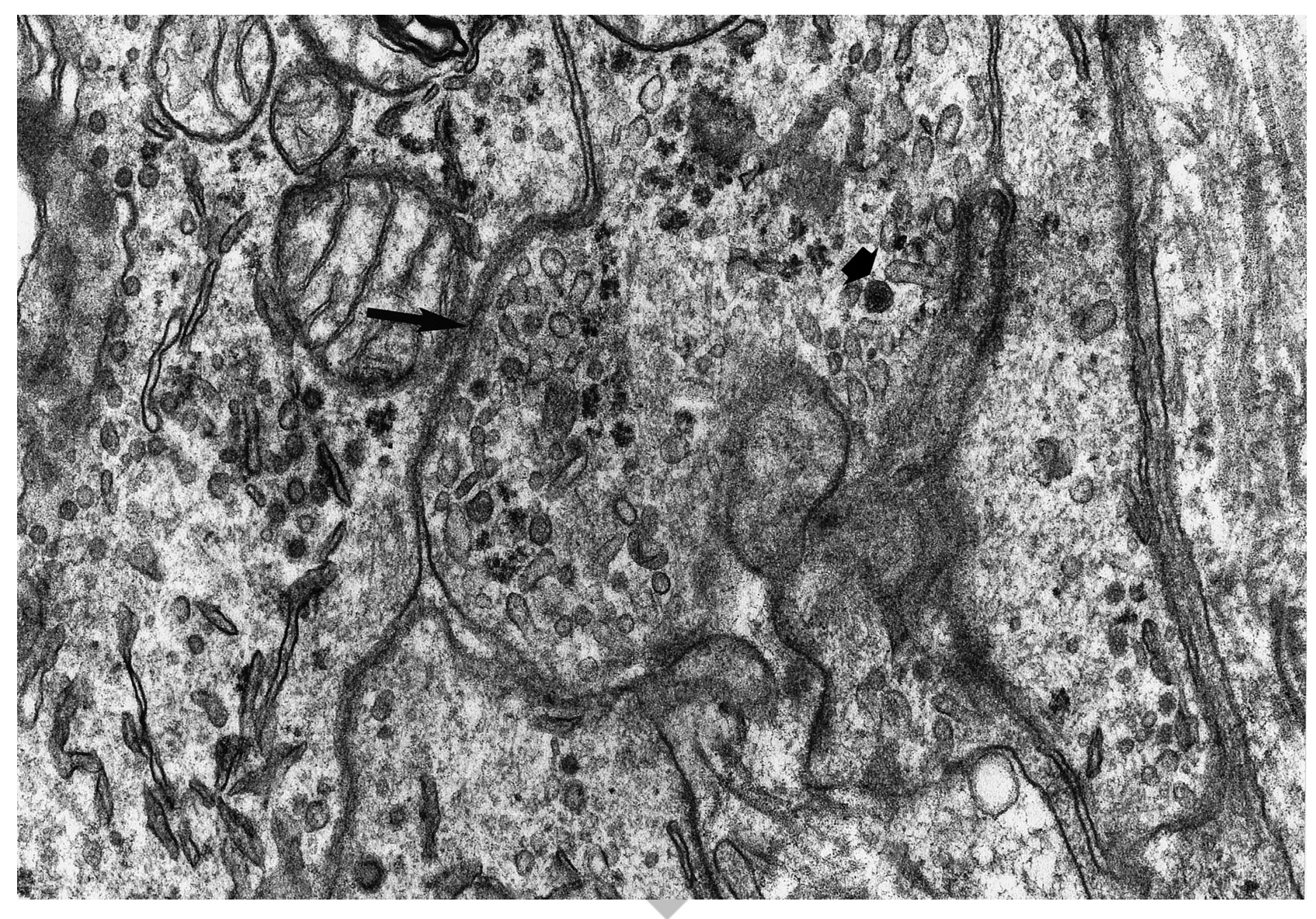

FIGURE 3. Part of the tumor cell showing bulbous axonlike processes with small empty vesicles (arrow) and a dense core granule (arrowhead) Magnification, $1,600 \times$.

Fluorescence in situ hybridization results were further confirmed by CGH analysis (Table 2). One tumor (Case 2) exhibited several genetic imbalances, whereas three others showed only few changes. Nevertheless, the common findings in all specimens by CGH were partial losses of chromosome 22, with the smallest region of deletion encompassing the 22q13 region. Notably, it was the only change detectable by CGH analysis in tumor from Patient 3.

\section{c-KIT Mutation Analysis}

All tumors exhibited mutations of c-KIT. In Cases 2 and 5 , the insertions of exon 9 were found, whereas other specimens showed mutations of exon 11 of the c-KIT gene (Table 2). In the samples of Patient 1, a single point mutation of codon 576 of exon 11 was present in both the primary and the secondary tumor, indicating that the later onset of the disease was due to the recurrence of the previous malignancy.

\section{DISCUSSION}

Electron microscopic examination is generally accepted as indispensable for the reliable diagnosis of GANTs. Ultrastructurally, the presence of dense core granules, cell processes, neurotubules, dystrophic axons, synapselike structures, and skeinoid fibers are characteristic for these tumors $(2,6,7,25)$. All our five cases fulfilled the ultrastructural criteria for GANT diagnosis. Simultaneously, all our cases carried c-KIT mutations that validated their classification within the general category of CD117positive GISTs. The presence of c-KIT mutations in 5 of 10 examined GANTs was recently reported by Lee and coworkers (8), proving that in this aspect GANTs do not differ from classical GISTs. In the previous study, we demonstrated the loss of the part $14 \mathrm{q}$ in two of four primary GANTs (15). Another GANT analyzed in this study did not disclose chromosome 14 loss in the primary tumor, whereas the subpopulation of cells from the recurrent sample indicated partial $14 \mathrm{q}$ loss. This finding suggests that at least in this particular case, the chromosome 14 loss was a secondary event, most likely associated with tumor progression. On the other hand, either primary and recurrent tumors from this patient revealed loss of the terminal part of the long arm of chromosome 22. By CGH and FISH analysis, all other GANTs analyzed in our study also demonstrated the loss of genetic material from chromo- 
TABLE 2. Cytogenetic and Molecular Findings of Five GANTs Under Study

\begin{tabular}{|c|c|c|c|c|c|c|}
\hline \multirow{2}{*}{ Number } & \multirow{2}{*}{$\mathrm{T}$} & \multirow{2}{*}{ Karyotype } & \multicolumn{2}{|c|}{ FISH Results (\% of cells) } & \multirow{2}{*}{ CGH } & \multirow{2}{*}{ c-KIT Mutations } \\
\hline & & & 14q Loss & 22q Loss & & \\
\hline \multirow[t]{2}{*}{1.} & $\mathrm{P}$ & Not done & No loss & $\begin{array}{l}\text { 22q12-q13 } \\
(76 \%)\end{array}$ & $\operatorname{Rev}$ ish $\operatorname{dim}(\mathbf{2 2 q 1 3}, \underline{X})$ & $\begin{array}{l}\text { PM Ex11 } \\
\text { Codon } 576 \\
\text { CTT } \rightarrow \text { CCT }\end{array}$ \\
\hline & $\mathrm{R}$ & No mitosis & $\begin{array}{c}\text { 14q11-q32 } \\
(38 \%)\end{array}$ & $\begin{array}{l}\text { 22q11-q12 } \\
(40 \%) \\
\text { 22q12-q13 } \\
(87 \%)\end{array}$ & $\operatorname{Rev}$ ish $\operatorname{dim}(\mathbf{2 2 q 1 3}, \underline{X})$ & $\begin{array}{l}\text { PM Ex11 } \\
\text { Codon } 576 \\
\text { CTT } \rightarrow \text { CCT }\end{array}$ \\
\hline 2. & $\mathrm{P}$ & $46, \mathrm{XX}[20]^{a}$ & No loss ${ }^{a}$ & $\begin{array}{l}\text { 22q12-q13 } \\
(91 \%)\end{array}$ & $\begin{array}{l}\text { Rev ish enh } \\
\text { (8p22p21,8q23q24, } \\
\text { 9q22q31,16q22,19q13), } \\
\text { dim(11p13p11,12p,22q12q13) }\end{array}$ & $\begin{array}{l}\text { Ins Ex9 } \\
\text { Codon } 502 / 503\end{array}$ \\
\hline 3. & $\mathrm{P}$ & No mitosis ${ }^{a}$ & No loss ${ }^{a}$ & $22 q 13(80 \%)$ & Rev ish dim (22q13) & $\begin{array}{l}\text { D Ex11 } \\
1694^{b} \text { del } 6 \text { bp }\end{array}$ \\
\hline 4. & $\mathrm{P}$ & $46, \mathrm{XY}[15]^{a}$ & $\begin{array}{l}\mathbf{1 4 q 2 3 - q 2 4}^{a} \\
\quad(55 \%)\end{array}$ & $\begin{array}{l}\text { 22q12-q13 } \\
(97 \%)\end{array}$ & $\begin{array}{l}\text { Rev ish enh (Xq21q22), dim } \\
\text { (17p,22q12q13) }\end{array}$ & $\begin{array}{l}\text { PM + D Ex11 } \\
\text { Codon } 558 \\
\text { AAG } \rightarrow \text { GAG } \\
1698^{b} \text { del } 6 \text { bp }\end{array}$ \\
\hline 5. & $\mathrm{P}$ & $\begin{array}{l}\text { 43,XY,-1,der(2;17)(q10;q10), } \\
\quad+5, \operatorname{del}(13)(\mathrm{q} 14) \\
\quad \operatorname{der}(14) \mathrm{t}(1 ; 14)(\mathrm{q} 11 ; \mathrm{q} 11) \\
\quad-15,-18,-22,+\operatorname{mar}[20]^{a}\end{array}$ & $\begin{array}{c}\mathbf{1 4 q 1 1 - q 3 2}^{a} \\
(93 \%)\end{array}$ & $\begin{array}{l}\text { 22q11-q13 } \\
(96 \%)\end{array}$ & Not done & $\begin{array}{l}\text { Ins Ex9 } \\
\text { Codon } 502 / 503\end{array}$ \\
\hline
\end{tabular}

\footnotetext{
${ }^{a}$ Published before (15).

${ }^{b}$ The nucleotide number at which the deletion started is based on previously published cDNA KIT sequences, available at GB HSKITCR, accession \#X06182.

T, tumor sample; P, primary; R, recurrent; Ex, exon; PM, point mutation; D, deletion; Ins, insertion.
}

some $22 \mathrm{q}$, with the common overlapping area of loss at q13. Our results indicate that GISTs showing neurogenic differentiation are characterized by an accumulation of a number of genetic changes; it may explain their frequently observed more aggressive clinical behavior $(6,18)$. Furthermore, our data suggest that the loss of the 22q13 chromosomal region may be a common feature of these tumors. So far, few tumor suppressor genes have been localized in 22q. One of them is NF2, a gene inactivated in neurofibromatosis 2-associated and sporadic schwannomas, perineurial cell tumors, and meningiomas (26-28). Fukasawa and coworkers (17) identified NF2 gene mutation in two of 22 GISTs investigated. The authors concluded that NF2 contributes as a tumor suppressor in a small subset of GIST. By FISH analysis, NF2 loci were lost in four of five tumors we investigated. In the tumor from Patient 3, however, the NF2 locus was preserved, suggesting the gene or genes localized more telomeric to NF2 to be involved in the pathogenesis of GANTs. Alternatively, the loss of the $22 \mathrm{q} 13$ region could be related to the progression of our tumors. The percentage of aggressive cases is generally higher in intestinal than gastric GISTs (29), and all five tumors in the present study were intestinal in origin and clinically progressive. Apparently, additional molecular studies are needed to further define the critical rêgion of $22 \mathrm{q}$ loss and to establish genes potentially responsible for the neurogenic differentiation of GANTs and/or their generally malignant clinical course.

In summary, we have used molecular cytogenetic methodologies and sequencing analysis to evaluate c-KIT mutations and chromosome 14q/ $22 \mathrm{q}$ losses in five ultrastructurally confirmed GANTs. c-KIT mutations and loss of 22q13-qter region were consistent in these tumors, suggesting that these alterations may be vital to the development and/or progression of GISTs with neuronal characteristics.

TABLE 3. Loss/Deletion of Chromosome 22q by FISH Analysis in Five GANT Cases

\begin{tabular}{cccccc}
\hline \multirow{2}{*}{ Case } & \multicolumn{5}{c}{ Probe/22q Region Mb from pter } \\
\cline { 2 - 6 } & DGCR/q11.2 17.0 & BCR/q11.2 20.2 & EWS/q12 26.3 & NF2/q12 26.6 & ARSA/q13.3 47.5 \\
\hline $1^{a}$ & + & + & + & $\mathrm{D}$ & $\mathrm{D}$ \\
$1^{b}$ & $\mathrm{D}$ & $\mathrm{D}$ & $\mathrm{D}$ & $\mathrm{D}$ & $\mathrm{D}$ \\
2 & + & + & $\mathrm{D}$ & $\mathrm{D}$ & $\mathrm{D}$ \\
3 & + & + & + & $\mathrm{D}$ & $\mathrm{D}$ \\
4 & + & + & $\mathrm{D}$ & $\mathrm{D}$ & $\mathrm{D}$ \\
5 & $\mathrm{D}$ & $\mathrm{D}$ & $\mathrm{D}$ & $\mathrm{D}$ & $\mathrm{D}$ \\
\hline
\end{tabular}

\footnotetext{
${ }^{a}$ Primary tumor.

${ }^{b}$ Recurrent tumor.

(D) deleted-one signal detected in more than $25 \%$ of interphase nuclei; (+) no loss.
} 
Acknowledgments: The authors thank Belinda Carleer, Boudewijn Hopman, and Lut Mekers for their excellent technical assistance.

\section{REFERENCES}

1. Miettinen M, Lasota J. Gastrointestinal stromal tumors: definition, clinical, histologic, immunohistochemical, and molecular genetic features and differential diagnosis. Virchows Arch 2001;438:1-12.

2. Kindblom L-G, Remotti HE, Aldenborg F, Meis-Kindblom JM. Gastrointestinal pacemarker cell tumor (GIPACT). Gastrointestinal stromal tumors show phenotypic characteristics of the interstitial cells of Cajal. Am J Pathol 1998;152: 1259-69.

3. Sarlomo-Rikala M, Kovatich A, Barusevicius A, Miettinen M. CD117: a sensitive marker for gastrointestinal stromal tumors that is more specific than CD34. Mod Pathol 1998;11: 728-34.

4. Herrera GA, de Moraes HP, Grizzle WE, Han SG. Malignant small bowel neoplasm of enteric plexus derivation (plexosarcoma). Dig Dis Sci 1984;29:215-84.

5. Walker P, Dvorak AM. Gastrointestinal autonomic nerve (GAN) tumor: ultrastructural evidence for a newly recognized entity. Arch Pathol Lab Med 1986;110:309-16.

6. Lauwers GY, Erlandson RA, Casper ES. Gastrointestinal autonomic nerve tumors. Am J Surg Pathol 1993;17:887-97.

7. Erlandson RA, Klimstra DS, Woodruff JM. Subclassification of gastrointestinal stromal tumors based on evaluation by electron microscopy and immunohistochemistry. Ultrastruct Pathol 1996;20:373-93.

8. Lee JR, Joshi V, Griffin JW, Lasota J, Mietinen M. Gastrointestinal autonomic nerve tumor. Immunohistochemical and molecular identity with gastrointestinal stromal tumor. Am J Surg Pathol 2001;25:979-87.

9. Hirota S, Isozaki K, Moriyama Y, Hashimoto K, Nishida T, Ishiguro S, et al. Gain-of-function mutations of c-kit in human gastrointestinal stromal tumors. Science 1998;279:57780.

10. Lux ML, Rubin BP, Biase TL, Chen C-J, Maclure T, Demetri $\mathrm{G}$, et al. KIT extracellular and kinase domain mutations in gastrointestinal stromal tumors. Am J Pathol 2000;156:791-5.

11. Taniguchi M, Nishida T, Hirota S, Isozaki K, Ito T, Nomura T, et al. Effect of c-kit mutation on prognosis of gastrointestinal stromal tumors. Cancer Res 2000;59:4297-300.

12. Lasota J, Wozniak A, Sarlomo-Rikala M, Rys J, Kordek R, Nassar A, et al. Mutations in exon 9 and 13 of KIT gene are rare events in gastrointestinal stromal tumors. A study of 200 cases. Am J Pathol 200;157:1091-5.

13. El-Rifai W, Sarlomo-Rikala M, Andersson LC, Knuutila S, Miettinen M. DNA sequence copy number changes in gastrointestinal stromal tumors: tumor progression and prognostic significance. Cancer Res 2000;60:3899-403.

14. El-Riffai W, Sarlomo-Rikala M, Andersson LC, Miettinen M, Knuuttila S. High-resolution deletion mapping of chromosome 14 in stromal tumors of the gastrointestinal tract suggests two distinct tumor suppressor loci. Genes Chromosom Cancer 2000;27:387-91.
15. Debiec-Rychter M, Sciot R, Pauwels P, Schoenmakers E, Dal Cin P, Hagemeijer A. Molecular cytogenetic definition of three distinct chromosome 14q deletion intervals in gastrointestinal stromal tumors. Genes Chromosom Cancer 2001; 32:26-32.

16. Kim N-G, Kim JJ, Ahn J-Y, Seong C-M, Nph SH, Kim CB, et al. Putative chromosomal deletions on $9 p, 9 q$ and $22 q$ occur preferentially in malignant gastrointestinal stromal tumors. Int J Cancer 2000;85,633-8.

17. Fukasawa T, Chong J-M, Sakurai S, Koshishi N, Ikeno R, Tanaka A, et al. Allelic loss of $14 \mathrm{q}$ and 22q, NF2 mutation, and genetic instability occur independently of c-kit mutation in gastrointestinal stromal tumor. Jpn J Cancer Res 2000;91:1241-9.

18. Meesters B, Pauwels PA, Pijnenburg AM, Vlasveld LT, Repelaer van Driel OJ. Metastasis in a "benign" duodenal stromal tumour. Eur J Surg Oncol 1998;24:334-5.

19. Heiden T, Wang N, Bernhard T. An improved Hedley method for preparation of paraffin-embedded tissues for flow-cytometric analysis of ploidy and S-phase. Cytometry 1991;12:614-21.

20. Dierlamm J, Wlodarska I, Michaux L, La Starza R, Zeller W, Mecucci C, et al. Successful use of the same slide for consecutive fluorescence in situ hybridization experiments. Genes Chromosom Cancer 1996;16:261-4.

21. Kallioniemi A, Kallioniemi OP, Sudar D, et al. Comparative genomic hybridization for molecular cytogenetic analysis of solid tumors. Science 1992;258:818-21.

22. Franke S, Wlodarska I, Maes B, Vandenberghe P, Delabie J, Hagemeijer A, et al. Lymphocyte predominance Hodgkin's disease is characterized by recurrent genomic imbalances. Blood 2001;97:1845-53.

23. Lasota J, Jasinski M, Sarlomo-Rikala M, Miettinen M. Mutations in exon 11 of c-kit occur preferentially in malignant versus benign gastrointestinal stromal tumors and do not occur in leiomyomas or leiomyosarcomas. Am J Pathol 1999; 154:53-60.

24. Miettinen M, Sarlomo-Rikāla M, Lasota J. KIT Expression in angiosarcomas and early fetal endothelial cells and lack of c-kit mutations in angiosarcomas. Mod Pathol 2000;13:53641.

25. Donner LR. Gastrointestinal autonomic nerve tumor: a common type of gastrointestinal stromal neoplasm. Ultrastruct Pathol 1997;21:419-24.

26. Louis DN, Ramesh V, Gusella JF. Neuropathology and molecular genetics of neurofibromatosis 2 and related tumors. Brain Pathol 1995;5:163-72.

27. Sciot R, Dal Cin P, Hagemeijer A, De Smet L, Van Damme B, Van den Berghe $\mathrm{H}$. Cutaneous sclerosing perineurioma with cryptic NF2 gene deletion. Am J Surg Pathol 1999;23:849-53.

28. Lasota J, Fetsch JF, Wozniak A, Wasag B, Sciot R, Miettinen $\mathrm{M}$. The neurofibrosis type 2 gene is mutated in perineurial cell tumors: a molecular genetic study of eight cases. Am J Pathol 2001;158:123-9.

29. Moskaluk CA, Tian Q, Marshall CR, Rumpel CA, Franquemont DW, Frierson HF Jr. Mutations of c-kit JM domain are found in a minority of human gastrointestinal stromal tumors. Oncogene 1999;18:1897-902. 